\title{
Analysis of the interaction of induction regimens with p-glycoprotein expression in patients with acute myeloid leukaemia: results from the MRC AML15 trial
}

\author{
M Pallis ${ }^{1}$, R Hills $^{2}, \mathrm{P}$ White ${ }^{2}, \mathrm{M}$ Grundy ${ }^{1,3}, \mathrm{~N}$ Russell ${ }^{1,3}$ and A Burnett ${ }^{2}$ on behalf of the NCRI AML working group, UK \\ ${ }^{1}$ Clinical Haematology, Nottingham University Hospitals, Nottingham, UK; ${ }^{2}$ Department of Haematology, Cardiff University, \\ Cardiff, UK and ${ }^{3}$ Division of Haematology, University of Nottingham, Nottingham, UK
}

\begin{abstract}
Retrospective analyses in non-randomised cohorts suggest that regimens containing fludarabine/Ara $\mathrm{C}$ and/or idarubicin/ ara $\mathrm{C}$ may be more effective than daunorubicin/AraC (DA)containing regimens in cases of acute myeloid leukaemia (AML) overexpressing p-glycoprotein (Pgp). We prospectively measured Pgp protein and function by flow cytometry in CD45gated blasts from 434 AML15 trial patients randomised to remission induction therapy with two courses of FLAG-Ida or DA \pm etoposide (DA/ADE). In all, $34 \%$ were positive for Pgp protein and $38 \%$ for function. Pgp protein-positive cases had a higher incidence of resistant disease ( $14 \%$ vs $5 \%$ ), adjusted odds ratio $2.67(1.14-6.24)$. There was a trend towards a higher cumulative incidence of relapse at 5 years for Pgp-positive cases (46\% vs $55 \%)$, adjusted hazard ratio 1.42 (0.98-2.07) $(P=0.06)$. For patients treated with FLAG-Ida, the complete remission (CR) rate was $86 \%$ for both Pgp-positive and Pgp-negative patients. In patients treated with DA/ADE, $78 \%$ of Pgp-positive and $\mathbf{9 0 \%}$ of Pgp-negative cases achieved CR $(P=0.06)$. In analyses of overall survival, there was no interaction between treatment received and Pgp expression. Data for Pgp function followed similar trends. Our data suggest that FLAG-Ida may improve the remission rate for Pgp-positive $A M L$, but the malignant clone is reduced rather than eradicated such that the relapse rate remains high in Pgp-positive patients. Blood Cancer Journal (2011) 1, e23; doi:10.1038/bcj.2011.23; published online 17 June 2011
\end{abstract}

Keywords: p-glycoprotein; trial; AML; multi-drug resistance

\section{Introduction}

P-glycoprotein (Pgp) is expressed in the plasma membrane of blast cells in $\sim 40 \%$ patients with acute myeloid leukaemia (AML). ${ }^{1}$ Pgp functions as a drug efflux pump that can account for the failure of many drugs to reach their intracellular targets. Such drugs include the common AML-treatment drugs daunorubicin and etoposide. Overexpression of Pgp by AML blasts is well established as a determinant of resistance to remissioninduction chemotherapy, and confers inferior disease-free survival and overall survival (OS) in patients receiving conventional anthracycline-containing remission-induction regimens. $^{2,3}$

Attempts to improve outcome by including a Pgp-reversal agent in clinical trials have largely been unsuccessful. ${ }^{4}$ Some clinical benefit was shown in a study in relapsed patients from the Southwest Oncology Group using cyclosporin as a

Correspondence: Dr M Pallis, Academic Haematology, Nottingham University Hospitals, Clinical Sciences Building, NUH City Campus, Nottingham NG5 1PB, UK.

E-mail: Monica.Pallis@nottingham.ac.uk

Received 21 January 2011; revised 30 March 2011; accepted 27 April 2011 modulator of daunorubicin given by continuous infusion. ${ }^{5}$ This trial showed a superior response rate and OS in relapsed patients in the cyclosporin arm. Cyclosporin also appeared to have some benefit in a non-randomised comparison of previously untreated elderly patients, with an improved complete remission (CR) rate for Pgp-positive patients treated with the modulator. ${ }^{6}$ Cyclosporin is thought not to be an ideal choice as a modulator because of its immunosuppressive properties and its potential for nephrotoxicity. The cyclosporin analogue PSC-833 had the potential benefit of less immunosuppression and renal toxicity, but trials of PSC-833 have failed to show benefit. ${ }^{7-11}$ The thirdgeneration agent zosuquidar has also failed to show significant benefit in a randomised trial. ${ }^{12}$

The FLAG (Fludarabine, Ara-C plus G-CSF) regimen with or without the addition of idarubicin (FLAG-Ida) has featured in several studies as induction therapy for relapsed AML and for patients who failed to achieve remission with standard daunorubicin and Ara-C (DA) regimens, ${ }^{13,14}$ and has been a successful strategy in refractory AML with documented Pgp-induced multidrug resistance. ${ }^{14}$ The cytotoxicity of FLAG is from the individual toxicities of fludarabine and Ara-C and from the potentiation of Ara-C toxicity by fludarabine and G-CSF. As fludarabine and Ara-C are not Pgp-substrate drugs, this combination may be effective at bypassing Pgp-related resistance mechanisms in primary AML cells. Pgp-related FLAG toxicity has also been studied in vitro: using the MRK16 antibody to define Pgp positivity, we found a clear advantage for DA treatment in Pgp-negative AML samples but, in contrast, Pgp-positive AML cells were found to be more responsive to FLAG than to DA. ${ }^{15}$ Furthermore AML cells with the highest expression of Pgp had the greatest differential response to FLAG. ${ }^{15}$ Furthermore, a group of centres, which had been using FLAG for remission induction in de novo $\mathrm{AML}$, published a case-control study of Pgp and induction regimens with and without fludarabine, which suggested that this agent was of benefit in Pgp-positive cases. ${ }^{16}$ Idarubicin is also of potential benefit in Pgp-positive AML cases. Although the drug is effluxed by Pgp, its increased lipophilicity and thus enhanced uptake leads to greater toxicity compared with daunorubicin in drugresistant cells. ${ }^{17,18}$ Pgp did not affect clinical responses to idarubicin-containing remission-induction therapy ${ }^{19}$ and appeared not to confound response to idarubicin monotherapy in heavily pre-treated patients. ${ }^{20}$

One study of FLAG with idarubicin (FLAG-Ida) used as firstline $\mathrm{AML}$-induction therapy produced a CR rate of $82 \%$, ${ }^{21}$ confirming the efficacy of this regimen and providing a rationale for comparison with daunorubicin and Ara-C (DA), as FLAG-based regimens had never been compared with DA in a randomised way for remission-induction therapy in de novo AML. This was one of the principal questions addressed by the MRC AML15 Trial. This trial therefore represented an opportunity 
to link a study of the interaction of Pgp with different induction regimens within a large randomised trial of $\mathrm{AML}$ therapy. Patients in AML15 were randomised to receive DA, ADE or FLAG-Ida with an additional randomisation to Mylotarg.

\section{Methods}

\section{Patients}

The AML15 trial was open to all patients with de novo or secondary AML aged 15-60 years, and also to patients aged 60 years or over for whom intensive therapy was considered appropriate. Amendments were made to the AML15 protocol during the course of the trial, but samples used in this study were collected before June 2006 which covered a period when the remission-induction randomisations (in non-M3 patients) were to receive one of three induction regimens $\mathrm{ADE}$, DA or FLAG-Ida for the first two courses of treatment with an additional randomisation to Mylotarg $\left(3 \mathrm{mg} / \mathrm{m}^{2}\right)$ given on day 1 of course 1 . Details, including a cohort diagram, are published elsewhere. ${ }^{22}$ Results of the randomisation to Mylotarg are not included in the current analysis; previous work showed no interaction for outcomes of the Mylotarg randomisation with Pgp. ${ }^{22}$ Patients not scheduled for transplant were randomised after course 2 to two further courses comprising amsacrine, Ara-C, etoposide (MACE) and mitozantrone and Ara-C (MidAc) or high-dose Ara-C at one of two doses (3 or $1.5 \mathrm{~g} / \mathrm{m}^{2}$ ), in a $2: 1: 1$ randomisation, and to receive or not a fifth course of chemotherapy.

\section{Laboratory analysis}

Presentation of bone marrow or peripheral blood samples $(n=464)$ for Pgp analysis were taken into preservative-free heparin or into EDTA tubes and sent to one of two laboratories in Nottingham and Cardiff between 2002 and 2006. Pgp was not measured in patients with M3 AML. Children were also excluded due principally to the large number of tests that needed to be performed on limited material, but also because prognostically significant Pgp overexpression is uncommon in pediatric cases. ${ }^{23,24}$ Details of the methodology and of the reproducibility studies undertaken to ensure agreement between the two laboratories are published elsewhere., ${ }^{1,26}$ Briefly Pgp protein was measured using the MRK16 antibody and function was measured using modulation by PSC-833 of rhodamine 123 retention. Cells were counterstained with CD45 to identify the blast (CD45low/side scatter low) population in flow-cytometric analysis.

\section{Definition of endpoints}

The outcome definitions used follow the international guidelines of Cheson et al. ${ }^{27}$ In the original protocol, patients did not require peripheral count recovery to achieve $C R$; however, in this report, CR required neutrophil recovery to $1.0 \times 10^{9} / \mathrm{l}$ and platelets to $100 \times 10^{9} /$, without evidence of extramedullary disease. Patients who achieved CR according to the protocol, but without recovery are denoted here as CRi. Remission failures were classified by the investigating clinician as due to induction death (death related to treatment and/or hypoplasia within 30 days), or resistant disease (failure to eliminate disease, including partial remissions). Where clinician evaluation was not available, deaths within 30 days were deemed induction death and other failures resistant disease. All percentages are quoted at 5 years.
Statistical analysis

Details of the clinical endpoints are as published previously ${ }^{22}$ and are in line with IWG Guidelines. ${ }^{27}$ Mantel-Haenszel and $\chi^{2}$-tests were used to test for differences in demographical and clinical data by Pgp status. Kaplan-Meier curves were constructed for survival data and compared by means of the logrank test. Multivariate Cox models were used to analyze cumulative incidence of relapse and OS. Multivariate models were adjusted for factors as specified and interactions were tested using the deviance. Surviving patients were censored at 1 January 2009, with follow-up complete for 97\% of patients. Hazard ratios and 95\% confidence intervals are quoted for endpoints. In all cases a ratio of $<1$ indicates benefit for higher Pgp levels. All $P$-values are two-tailed.

\section{Results}

\section{Demographics and laboratory correlates}

Demographic data are displayed in Table 1. Patients were primarily under 60 , although $13 \%$ of the cohort studied for Pgp was older. Of the 464 samples processed, there were sufficient viable cells to measure protein and/or function in 434 and both in 348. Pgp protein was measured in 368 samples and Pgp function in 412 . in all, $34 \%$ of cases were positive for Pgp protein and $38 \%$ for function (23\% low and $15 \%$ high). The median age of this cohort was 48. Table 1 incorporates an examination of factors previously indicated to be associated with Pgp expression, such as age, white cell count, cytogenetics and secondary AML. ${ }^{1,28}$ In this relatively young cohort, with less secondary AML or adverse cytogenetics than in the elderly, Pgp positivity remained associated with age $(P=0.01)$ and with a lower white count $(P=0.002)$ (Table 1$)$. Comparison with contemporaneous adult trial patients with non-APL AML not included in this data set $(n=1166)$, demonstrated that there were no significant differences in age, sex, performance status or cytogenetic group between patients with data on Pgp and those without, although patients in this study were slightly less likely to have secondary disease ( $6 \%$ vs $9 \%, P=0.05$ ) and had slightly higher white blood cell count (median $13.2 \%$ vs 9.7, $P=0.02$ ) than those in the rest of AML15. Outcomes, however, were similar between groups.

\section{Effect of Pgp on outcome in the entire cohort}

Overall, Pgp was associated with an inferior $\mathrm{CR}$ rate in unadjusted analysis-odds ratio (OR) 1.91 (1.03-3.55) $P=0.04$, Table 2, but did not significantly affect the CR rate after adjustment for age, WBC, sex, secondary disease, performance status and cytogenetics (standard co-variates in MRC AML Trial analysis). ${ }^{22}$ As Pgp might be expected to affect the cellular response to chemotherapy, but not to have an effect on induction deaths, we also studied primary resistant disease. Pgp protein-positive cases had a higher incidence of primary resistant disease (14\% vs 5\%), adjusted OR 2.67 (1.14-6.24) $P=0.02$, Table 2 .

There was a trend towards a lower cumulative incidence of relapse at 5 years for Pgp-negative cases (46\% vs 55\%, adjusted hazard ratio $1.42 ; 0.98-2.07, P=0.06)$, but this did not translate into a significant survival benefit (Table 2). Results for Pgp function were similar, although the association with primary resistant disease was lost in the adjusted data set, whereas a marked association was noted between Pgp function and poor relapse-free survival (Table 3 and Figure 1). 


\begin{tabular}{|c|c|c|c|c|c|c|c|}
\hline & \multicolumn{3}{|c|}{ Pgp protein (number) } & \multicolumn{4}{|c|}{ Pgp function (number) } \\
\hline & Negative & Positive & $\mathrm{P}$ & Negative & Low & High & $P$ \\
\hline Age & & & $0.01^{a}$ & & & & $0.05^{a}$ \\
\hline$<15$ & 0 & 0 & & 1 & 0 & 0 & \\
\hline $15-29$ & 42 & 19 & & 32 & 25 & 4 & \\
\hline 30-39 & 42 & 13 & & 43 & 7 & 6 & \\
\hline $40-49$ & 56 & 23 & & 57 & 24 & 14 & \\
\hline $50-59$ & 83 & 44 & & 95 & 27 & 23 & \\
\hline $60-69$ & 21 & 25 & & 26 & 12 & 16 & \\
\hline $70+$ & 0 & 0 & & 0 & 0 & 0 & \\
\hline Sex & & & 0.03 & & & & $0.07^{a}$ \\
\hline Female & 126 & 49 & & 129 & 44 & 24 & \\
\hline Male & 118 & 75 & & 125 & 51 & 39 & \\
\hline Performance status & & & $0.18^{a}$ & & & & $0.11^{a}$ \\
\hline 0 & 156 & 88 & & 154 & 69 & 42 & \\
\hline 1 & 78 & 33 & & 87 & 22 & 20 & \\
\hline 2 & 6 & 1 & & 6 & 1 & 1 & \\
\hline 3 & 3 & 2 & & 5 & 3 & 0 & \\
\hline 4 & 1 & 0 & & 1 & 0 & 0 & \\
\hline Secondary disease & & & 0.6 & & & & $0.2^{\mathrm{a}}$ \\
\hline No & 233 & 120 & & 246 & 91 & 59 & \\
\hline Yes & 11 & 4 & & 8 & 4 & 4 & \\
\hline$W B C$ & & & $0.002^{\mathrm{a}}$ & & & & $<0.0001^{a}$ \\
\hline$<10$ & 71 & 57 & & 69 & 48 & 42 & \\
\hline 10-49.9 & 92 & 40 & & 98 & 31 & 12 & \\
\hline 50-99.9 & 43 & 18 & & 47 & 10 & 7 & \\
\hline $100+$ & 36 & 9 & & 38 & 6 & 2 & \\
\hline Unknown & 2 & 0 & & 2 & 0 & 0 & \\
\hline Cytogenetics & & & $0.4^{\mathrm{a}}$ & & & & $0.08^{a}$ \\
\hline Favourable & 35 & 20 & & 29 & 26 & 4 & \\
\hline Intermediate & 155 & 65 & & 166 & 42 & 33 & \\
\hline Adverse & 17 & 17 & & 15 & 12 & 12 & \\
\hline Unknown & 37 & 22 & & 44 & 15 & 14 & \\
\hline
\end{tabular}

${ }^{a}$ Mantel-Haenszel test for trend: all others test for heterogeneity.

Table 2 Responses of the entire cohort $(n=348)$ according to Pgp protein status

\begin{tabular}{lcccc}
\hline & Protein negative (\%) & Protein positive (\%) & $\begin{array}{c}\text { Unadjusted OR/HR, } \\
\text { 95\% Cl; P-value }\end{array}$ & $\begin{array}{c}\text { Adjusted OR/HR, } \\
\text { 95\% Cl; P-value }\end{array}$ \\
\hline CR/CRi & 89 & & $1.91(1.03-3.55) ; 0.04$ & $1.51(0.78-2.92) ; 0.2$ \\
Resistant disease & 5 & 14 & $3.35(1.50-7.46) ; 0.003$ & $2.67(1.14-6.24) ; 0.02$ \\
5-year OS & 46 & 33 & $1.27(0.95-1.71) ; 0.10$ & $1.13(0.82-1.55) ; 0.5$ \\
5-year RFS & 45 & 32 & $1.32(0.97-1.01) ; 0.08$ & $1.34(0.95-1.88) ; 0.09$ \\
5-year CIR & 46 & 55 & $1.33(0.94-1.88) ; 0.11$ & $1.42(0.98-2.07) ; 0.06$ \\
\hline
\end{tabular}

Abbreviations: $\mathrm{Cl}$, confidence interval; $\mathrm{CIR}$, cumulative incidence of relapse; $\mathrm{CR}$, complete remission; HR, hazard ratio; OR, odds ratio; OS, overall survival; Pgp, p-glycoprotein; RFS, relapse-free survival.

Impact of induction regimen on treatment outcome in Pgp-positive and -negative AML

The impact of individual induction regimens on initial response is shown in Table 4. For patients receiving DA/ADE-induction therapy the CR rate was lower in Pgp $+\mathrm{AML}$ compared with Pgp-negative cases (78\% compared with 90\%, OR 2.74 (1.27-5.89) $P=0.01)$. In contrast the CR rate for FLAG-Ida was $86 \%$ for both Pgp-positive and -negative patients (OR 0.97 (0.34-2.78) $P=1.0$ ). The adjusted $P$-value for the interaction between Pgp and induction treatment for CR rate was 0.06 .

For patients receiving $\mathrm{ADE} / \mathrm{DA}$, the incidence of primary resistant disease was $6 \%$ in the Pgp-negative cohort and $18 \%$ in
Pgp-positive cases, OR 3.84 (1.55-9.53), $P=0.004$, whereas no significant difference was observed between Pgp-positive and negative cases treated with FLAG/Ida. The $P$-value for interaction was 0.8 , but with such a low incidence of primary resistant disease in the trial, this comparison was underpowered for statistical analysis. There were no significant interactions association between Pgp function and CR rate.

We have reported that for all patients entered into the AML15 trial the cumulative incidence of relapse was lower for patients given FLAG-Ida compared with ADE. ${ }^{29}$ However, the cumulative incidence of relapse rate for Pgp-positive patients in both arms was greater than for Pgp-negative patients: the adjusted 
Table 3 Responses of the entire cohort $(n=412)$ according to Pgp function status

\begin{tabular}{lccccc}
\hline & $\begin{array}{c}\text { Function } \\
\text { negative (\%) }\end{array}$ & $\begin{array}{c}\text { Function } \\
\text { low (\%) }\end{array}$ & $\begin{array}{c}\text { Function } \\
\text { high (\%) }\end{array}$ & $\begin{array}{c}\text { Unadjusted OR/HR, } \\
\text { 95\% Cl; P-value }\end{array}$ & $\begin{array}{c}\text { Adjusted OR/HR, } \\
\text { 95\% Cl; P-value }\end{array}$ \\
\hline CR/CRi & 87 & 87 & 78 & $1.30(0.92-1.84) ; 0.14$ & $1.13(0.75-1.70) ; 0.6$ \\
Resistant disease & 6 & 6 & 17 & $1.78(1.16-2.76) ; 0.009$ & $1.45(0.88-2.40) ; 0.14$ \\
5-year OS & 46 & 42 & 28 & 1.17 (0.99-1.39); 0.06 & $1.12(0.93-1.36) ; 0.3$ \\
5-year RFS & 46 & 34 & 24 & $1.26(1.06-1.51) ; 0.01$ & $1.26(1.03-1.54) ; 0.02$ \\
5-year CIR & 47 & 52 & 63 & $1.24(1.02-1.51) ; 0.03$ & $1.27(1.02-1.59) ; 0.03$ \\
\hline
\end{tabular}

Abbreviations: $\mathrm{Cl}$, confidence interval; $\mathrm{CIR}$, cumulative incidence of relapse; $\mathrm{CR}$, complete remission; HR, hazard ratio; OR, odds ratio; OS, overall survival; Pgp, p-glycoprotein; RFS, relapse-free survival.
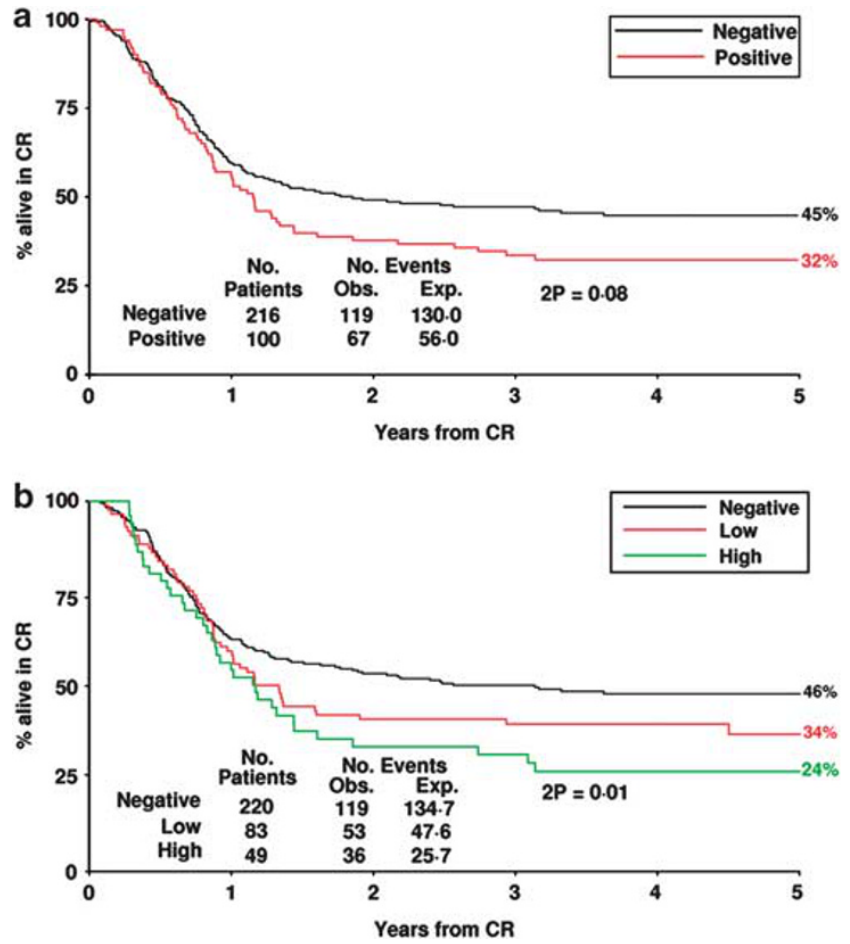

Figure 1 Relapse free survival stratified by (a) Pgp protein and (b) Pgp function.

$P$-value for the interaction with protein was 0.07 , and $P=0.4$ for function (Figure 2).

There was no significant interaction between Pgp protein or function and treatment group affecting OS (Figure 3): the adjusted $P$-values for the interaction were 0.4 for protein and 0.8 for function.

\section{Discussion}

A previous study of the interaction between Pgp and regimens with or without fludarabine (comprising fludarabine, AraC, idarubicin \pm etoposide) adopted an age-matched case-control strategy and found an improved CR rate, OS and disease-free survival for Pgp-positive patients with regimens containing fludarabine. ${ }^{16}$ In the randomised AML15 trial, results on CR are in agreement with this and show a CR/CRi rate of $86 \%$ for Pgppositive patients with FLAG-Ida, which was the same as that seen in Pgp-negative AML. In contrast, patients receiving induction regimens incorporating the Pgp substrates daunorubicin and etoposide (DA/ADE) had a lower CR rate if they were Pgp + . This is the second randomised controlled trial in de novo AML to have shown a benefit for an intervention in the Pgp + group.
Previously, quinine was also shown to improve the CR rate but not OS in Pgp + AML patients. ${ }^{30}$ Other strategies attempted, particularly the use of Pgp inhibition with PSC833 or zosuquidar, have failed to improve outcomes in this group of patients. ${ }^{7-12}$

Regarding relapse, results for AML15 previously reported showed that FLAG-Ida resulted in a reduced relapse rate overall compared with DA/ADE. ${ }^{29}$ Both Pgp-positive and -negative patients benefited in this respect from FLAG-Ida treatment, but in contrast to the case-control study, we found a significant interaction between Pgp and treatment received with respect to relapse rate, with Pgp-positive patients having a higher relapse rate than Pgp-negative patients in both treatment arms. Furthermore there was no interaction between Pgp and treatment received in effect on OS. Thus the use of FLAG-Ida induction in Pgp-positive cases induces a slight shift in initial efficacy, such that efficient clonal reduction results in improved CR for this subgroup, but these patients have an increased frequency of relapse with a consequent lack of effect on OS. These data suggest that in the most chemoresistant samples, the leukaemic clone is reduced rather than eradicated, such that relapse is high in these cases. Pgp is not necessarily overexpressed in all leukaemic stem and progenitor cells. However, we have previously determined that Pgp expression in the CD34 + CD38 subset, which contains the leukaemia initiating cells, correlates strongly with expression in the sample as a whole, suggesting that when a sample is Pgp positive, relapse is likely to be driven by Pgp-positive cells within this subpopulation. ${ }^{31}$ However, factors driving chemoresistance in the MRD cells of Pgp-negative samples remain to be determined. The suggestion that Pgp is acquired during the course of remission-induction chemotherapy is a possibility, but remains unproven. ${ }^{11,32,33}$ We investigated an alternative explanation for the altered CR and relapse rates in Pgp + patients treated with fludarabine-based regimens, namely that post-remission regimens, including use of stem cell transplants, may have differed. Consolidation regimens were randomised in the AML15 trial, although uptake in the FLAG-Ida arm of the trial was lower than in the ADE/DA part of the trial. Overall within AML15, as was demonstrated in the initial report of the results, ${ }^{29}$ significantly improved relapse-free survival was obtained with FLAG-Ida compared with daunorubicin-containing regimens. In the study reported here, rates of allogeneic transplantation were similar between groups (ADE/DA 20\%, FLAG-Ida 15\%, $P=0.2$ ). We therefore consider it unlikely that the results seen arise out of differences in post-remission treatment, although numbers are too small to rule this out with absolute certainty.

Slight distinctions between Pgp protein and function have been noted in this study and we have commented on this previously. ${ }^{1}$ We used PSC-833 in our functional assay and although this is more specific than other modulators in the literature, it has not been studied in genetic models of all 49 $\mathrm{ABC}$ transporters, and other efflux pumps may be affected in this 


\begin{tabular}{|c|c|c|c|}
\hline & $A D E / D A$ & FLAG & P-value for interaction \\
\hline \multicolumn{4}{|l|}{$\mathrm{CR} / \mathrm{CRi}$} \\
\hline Protein negative (\%) & $90(142 / 158)$ & $86(74 / 86)$ & Unadjusted: 0.1 \\
\hline Protein positive (\%) & $78(62 / 80)$ & $86(38 / 44)$ & Adjusted: 0.06 \\
\hline OR and $95 \% \mathrm{Cl}$ & $2.74(1.27-5.89)$ & $0.97(0.34-2.78)$ & \\
\hline Unadjusted $P$-value (protein) & $P=0.01$ & $P=1.0$ & \\
\hline Function negative (\%) & $87(141 / 163)$ & $87(78 / 90)$ & Unadjusted: 0.2 \\
\hline Low function (\%) & $89(57 / 64)$ & $84(26 / 31)$ & Adjusted: 0.15 \\
\hline High function (\%) & $71(30 / 42)$ & $90(19 / 21)$ & \\
\hline $\mathrm{OR}$ and $95 \% \mathrm{Cl}$ (per level) & $1.49(0.99-2.26)$ & $0.92(0.47-1.79)$ & \\
\hline Unadjusted $P$-value (function) & $P=0.06$ & $P=0.8$ & \\
\hline \multicolumn{4}{|l|}{ Resistant disease } \\
\hline Protein negative (\%) & $6(9 / 158)$ & $3(3 / 86)$ & Unadjusted: 0.5 \\
\hline Protein positive (\%) & $18(14 / 80)$ & $7(3 / 44)$ & Adjusted: 0.8 \\
\hline $\mathrm{OR}$ and $95 \% \mathrm{Cl}$ & $3.84(1.55-9.53)$ & $2.12(0.38-11.89)$ & \\
\hline Unadjusted $P$-value (protein) & $P=0.004$ & $P=0.4$ & \\
\hline Function negative (\%) & $8(13 / 163)$ & $2(2 / 90)$ & Unadjusted: 0.8 \\
\hline Low function (\%) & $6(4 / 64)$ & $6(2 / 31)$ & Adjusted: 0.9 \\
\hline High function (\%) & $24(10 / 42)$ & $5(1 / 21)$ & \\
\hline OR and $95 \% \mathrm{Cl}$ per level & $1.81(1.12-2.94)$ & $1.60(0.55-4.68)$ & \\
\hline Unadjusted $P$-value (function) & $P=0.02$ & $P=0.4$ & \\
\hline
\end{tabular}

Abbreviations: $\mathrm{Cl}$, confidence interval; $\mathrm{CR}$, complete remission; $\mathrm{OR}$, odds ratio.
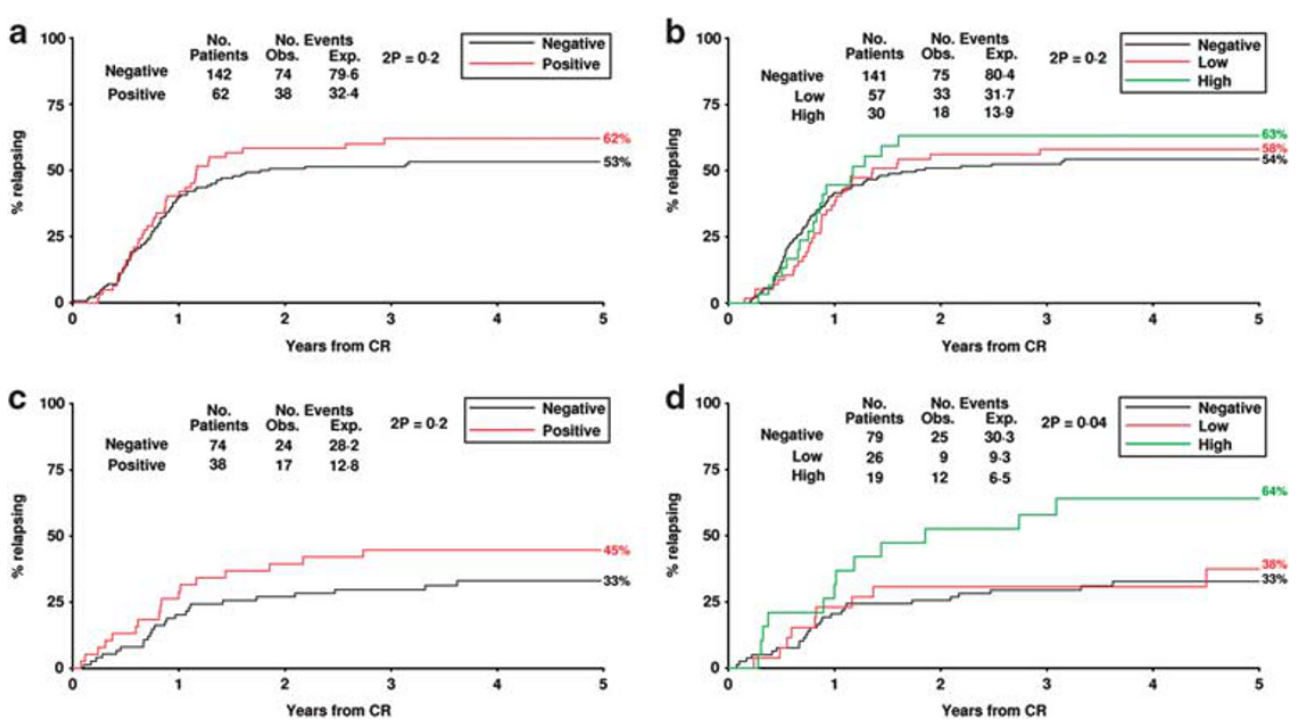

Figure 2 Relpase risk stratified by treatment, Pgp protein and Pgp function. (a) Pgp protein, DA/ADE; (b) Pgp function, DA/ADE; (c) Pgp protein, FLAG-Ida; and (d) Pgp function, FLAG-Ida.

assay. The major impact of functionally defined Pgp in our study was on relapse, so the possibility that the leukaemic stem cells that drive relapse have additional pumps affected in the functional assay is logical but completely speculative.

Our study shows a high CR/CRi rate in AML15 Pgp-positive patients compared with other studies reported in the literature. Table 5 represents a compilation of remission data, from studies in which the Pgp status of patients is known. Some studies comprised a wide range of patient ages, so we have selected those with a median age $<60$ to afford a reasonable comparison with our data. All patients were treated with chemotherapy containing ara-C and an anthracycline. The CR/CRi rate for Pgppositive adult patients in AML15 receiving FLAG-Ida was over $10 \%$ higher than that reported in these historical controls.

Only one report of those listed in Table 5 failed to show a difference in $C R$ rate between Pgp-positive and -negative patients: this study is notable in that idarubicin was used in preference to daunorubicin, and fludarabine was not included in the treatment protocol. ${ }^{19}$ This serves as a reminder that the effects we have observed in the current study maybe a result of the interaction between fludarabine and idarubicin or to either of these drugs individually. Prospective analysis of Pgp in clinical specimens has been hampered by a literature in the 1990s showing that Pgp is difficult to measure. More recently, however, multi-centre analysis of AML samples has shown that reliable, quick measurements of Pgp function are feasible. ${ }^{1,26}$ We hope that other groups using fludarabine and idarubicin will consider measuring Pgp in their patients.

In conclusion our data indicate that FLAG-Ida may improve the remission rate for Pgp-positive $\mathrm{AML}$, but the malignant clone is reduced rather than eradicated such that the relapse rate remains high in Pgp-positive patients, irrespective of 

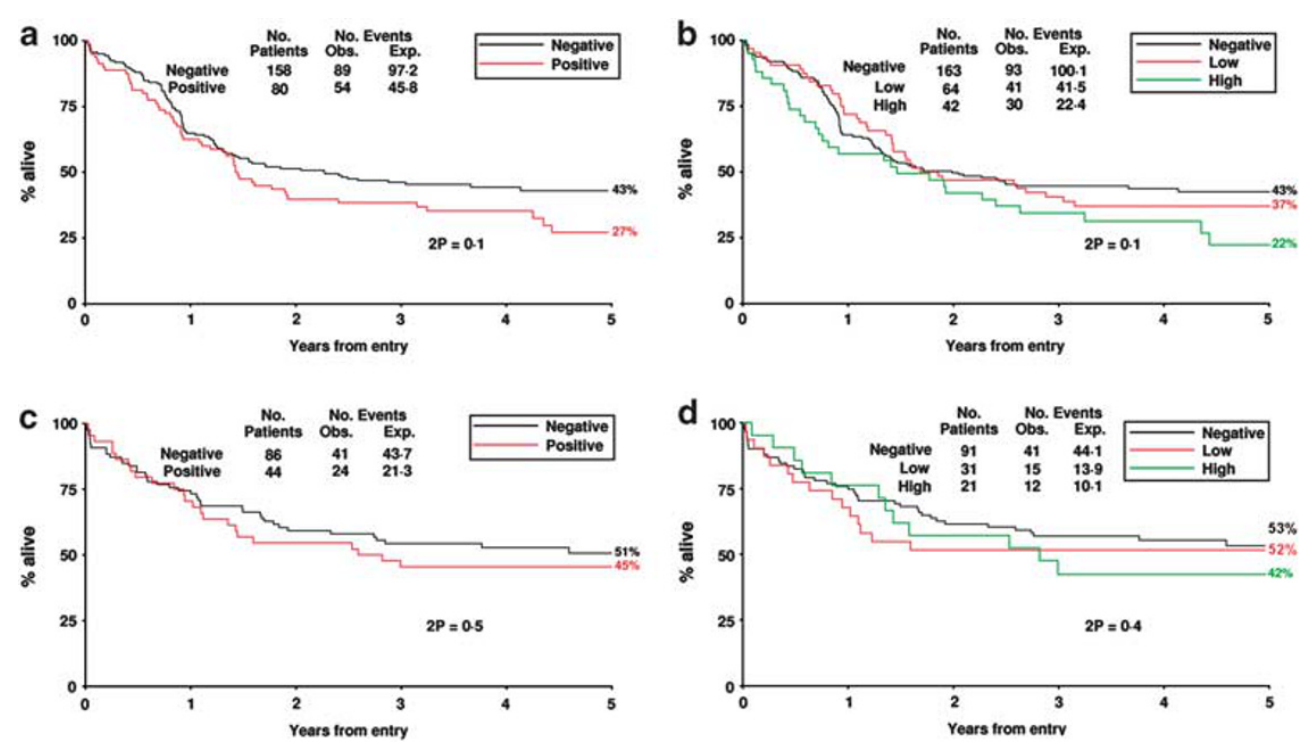

Figure 3 OS stratified by treatment, Pgp protein and Pgp function. (a) Pgp protein, DA/ADE; (b) Pgp function, DA/ADE; (c) Pgp protein, FLAG-Ida; and (d) Pgp function, FLAG-Ida.

Table 5 CR/CRi rates for Pgp-positive and -negative previously untreated patients with a median age $<60$ (listed in order of increasing median age)

\begin{tabular}{|c|c|c|c|}
\hline \multirow[t]{2}{*}{ Reference } & \multicolumn{2}{|c|}{ CR rate } & \multirow[t]{2}{*}{ Median age } \\
\hline & Pgp positive (\%) & Pgp negative (\%) & \\
\hline $\begin{array}{l}\text { Solary } \\
\text { Broxterman }^{19} \\
\text { Leith }^{34}\end{array}$ & $\begin{array}{c}67 \text { (CR) } \\
68 \text { (CR+CRi) } \\
48 \text { (CR) }\end{array}$ & $\begin{array}{c}82 \text { (CR) } \\
71 \text { (CR+CRi) } \\
54 \text { (CR) }\end{array}$ & $\begin{array}{l}41 \\
43 \\
44\end{array}$ \\
\hline $\begin{array}{l}\text { This study-overall } \\
\text { ADE/DA } \\
\text { FLAG-Ida }\end{array}$ & $\begin{array}{l}81 \text { (CR+CRi) (76 CR) } \\
78 \text { (CR+CRi) (71 CR) } \\
86 \text { (CR+CRi) (84 CR) }\end{array}$ & $\begin{array}{l}89 \text { (CR+CRi) (85 CR) } \\
90 \text { (CR+CRi) (85 CR) } \\
86 \text { (CR+CRi) (85 CR) }\end{array}$ & 48 \\
\hline $\begin{array}{l}\text { Van den Heuvel-Eibrink } \\
\text { Damiani }^{36} \\
\text { Marzac }^{37} \\
\text { Schaich }^{38} \\
\text { Del Poeta }^{39}\end{array}$ & $\begin{array}{l}36(\mathrm{CR}) \\
56(\mathrm{CR}) \\
41(\mathrm{CR}) \\
31(\mathrm{CR}) \\
40(\mathrm{CR})\end{array}$ & $\begin{array}{l}77(\mathrm{CR}) \\
85(\mathrm{CR}) \\
67(\mathrm{CR}) \\
56(\mathrm{CR}) \\
72(\mathrm{CR})\end{array}$ & $\begin{array}{l}51 \\
53 \\
54 \\
56 \\
57\end{array}$ \\
\hline
\end{tabular}

Abbreviations: CR, complete remission; Pgp, p-glycoprotein.

remission-induction therapy. However the high $C R$ rate obtained with FLAG-Ida in Pgp-positive AML may permit more patients to progress to allogeneic transplantation in first CR.

\section{Conflict of interest}

The authors declare no conflict of interest.

\section{Acknowledgements}

This study was supported by a project grant from Leukemia and Lymphoma Research. We thank all the people who have sent us samples.

\section{References}

1 Seedhouse $\mathrm{CH}$, Grundy M, White P, Li Y, Fisher J, Yakunina D et al. Sequential influences of leukemia-specific and genetic factors on p-glycoprotein expression in blasts from 817 patients entered into the National Cancer Research Network acute myeloid leukemia 14 and 15 trials. Clin Cancer Res 2007; 13: 7059-7066.
2 Leith C. Multidrug resistance in leukemia. Curr Opin Hematol 1998; 5: 287-291.

3 Pallis M, Turzanski J, Higashi Y, Russell N. P-glycoprotein in acute myeloid leukaemia: therapeutic implications of its association with both a multidrug-resistant and an apoptosis- resistant phenotype. Leuk Lymphoma 2002; 43: 1221-1228.

4 Mahadevan D, List AF. Targeting the multidrug resistance-1 transporter in AML: molecular regulation and therapeutic strategies. Blood 2004; 104: 1940-1951.

5 List AF, Kopecky KJ, Willman CL, Head DR, Persons DL, Slovak $\mathrm{ML}$ et al. Benefit of cyclosporine modulation of drug resistance in patients with poor-risk acute myeloid leukemia: a Southwest Oncology Group study. Blood 2001; 98: 3212-3220.

6 Chauncey TR, Gundacker H, Shadman M, List AF, Dakhil SR, Erba $\mathrm{HP}$ et al. Sequential phase II Southwest Oncology Group studies (S0112 and S0301) of daunorubicin and cytarabine by continuous infusion, without and with ciclosporin, in older patients with previously untreated acute myeloid leukaemia. $\mathrm{Br} J$ Haematol 2009; 148: 48-58.

7 Baer MR, George SL, Dodge RK, O'Loughlin KL, Minderman $\mathrm{H}$, Caligiuri MA et al. Phase 3 study of the multidrug resistance modulator PSC-833 in previously untreated patients 60 years of age and older with acute myeloid leukemia: Cancer and Leukemia Group B Study 9720. Blood 2002; 100: 1224-1232. 
8 Greenberg PL, Lee SJ, Advani R, Tallman MS, Sikic BI, Letendre L et al. Mitoxantrone, etoposide, and cytarabine with or without valspodar in patients with relapsed or refractory acute myeloid leukemia and high-risk myelodysplastic syndrome: a phase III trial (E2995). J Clin Oncol 2004; 22: 1078-1086.

9 van der Holt B, Lowenberg B, Burnett AK, Knauf WU, Shepherd J, Piccaluga PP et al. The value of the MDR1 reversal agent PSC-833 in addition to daunorubicin and cytarabine in the treatment of elderly patients with previously untreated acute myeloid leukemia (AML), in relation to MDR1 status at diagnosis. Blood 2005; 106: 2646-2654.

10 Burnett AK, Milligan D, Goldstone A, Prentice A, McMullin MF, Dennis $M$ et al. The impact of dose escalation and resistance modulation in older patients with acute myeloid leukaemia and high-risk myelodysplastic syndrome: the results of the LRF AML14 trial. Br J Haematol 2009; 145: 318-332.

11 Kolitz JE, George SL, Marcucci G, Vij R, Powell BL, Allen SL et al. P-glycoprotein inhibition using valspodar (PSC-833) does not improve outcomes for patients under age 60 years with newly diagnosed acute myeloid leukemia: Cancer and Leukemia Group B study 19808. Blood 2010; 116: 1413-1421.

12 Cripe LD, Uno H, Paietta EM, Litzow MR, Ketterling RP, Bennett JM et al. Zosuquidar, a novel modulator of P-glycoprotein, does not improve the outcome of older patients with newly diagnosed acute myeloid leukemia: a randomized, placebo-controlled, trial of the Eastern Cooperative Oncology Group (ECOG 3999). Blood 2010; 116: 4077-4085.

13 Visani G, Tosi P, Zinzani PL, Manfroi S, Ottaviani E, Testoni N et al. Flag (fludarabine plus high-dose cytarabine plus g-csf) - an effective a nd tolerable protocol for the treatment of poor-risk acute myeloid leukemias. Leukemia 1994; 8: 1842-1846.

14 Byrne JL, Dasgupta E, Pallis M, Turzanski J, Forman K, Mitchell D et al. Early allogeneic transplantation for refractory or relapsed acute leukaemia following remission induction with FLAG. Leukemia 1999; 13: 786-791.

15 Higashi $\mathrm{Y}$, Turzanski J, Pallis $\mathrm{M}$, Russell NH. Contrasting in vitro effects for the combination of fludarabine, cytosine arabinoside (Ara-C) and granulocyte colony-stimulating factor (FLAG) compared with daunorubicin and Ara-C in P-glycoprotein-positive and P-glycoprotein-negative acute myeloblastic leukaemia. $\mathrm{Br} / \mathrm{Hae}-$ matol 2000; 111: 565-569.

16 Malagola M, Damiani D, Martinelli G, Michelutti A, Cesana B, Vivo $\mathrm{AD}$ et al. Case-control study of multidrug resistance phenotype and response to induction treatment including or not fludarabine in newly diagnosed acute myeloid leukaemia patients. Br J Haematol 2007; 136: 87-95.

17 Mulder HS, Dekker H, Pinedo HM, Lankelma J. The P-glycoprotein-mediated relative decrease in cytosolic free drug concentration is similar for several anthracyclines with varying lipophilicity. Biochem Pharmacol 1995; 50: 967-974.

18 Mankhetkorn S, Dubru F, Hesschenbrouck J, Fiallo M, GarnierSuillerot A. Relation among the resistance factor, kinetics of uptake, and kinetics of the P-glycoprotein-mediated efflux of doxorubicin, daunorubicin, 8-(S)-fluoroidarubicin, and idarubicin in multidrugresistant K562 cells. Mol Pharmacol 1996; 49: 532-539.

19 Broxterman HJ, Sonneveld P, van Putten WJ, Lankelma J, Eekman CA, Ossenkoppele G) et al. P-glycoprotein in primary acute myeloid leukemia and treatment outcome of idarubicin/cytosine arabinosidebased induction therapy. Leukemia 2000; 14: 1018-1024.

20 Nussler V, Gieseler F, Zwierzina H, Gullis E, PelkaFleischer R, Diem $\mathrm{H}$ et al. Idarubicin monotherapy in multiply pretreated leukemia patients: Response in relation to P-glycoprotein expression. Annals Of Hematology 1997; 74: 57-64.

21 Clavio M, Gatto S, Beltrami G, Quintino S, Canepa L, Pierri I et al. Fludarabine, ARA-C, idarubicin and G-CSF (FLAG-Ida), high dose ARA-C and early stem cell transplant. A feasable and effective therapeutic strategy for de novo AML patients. J Exp Clin Cancer Res 2002; 21: 481-487.

22 Burnett AK, Hills RK, Milligan D, Kjeldsen L, Kell J, Russell NH et al. Identification of patients with acute myeloblastic leukemia who benefit from the addition of gemtuzumab ozogamicin: results of the MRC AML15 trial. J Clin Oncol 2011; 29: 369-377.

23 Sievers EL, Smith FO, Woods WG, Lee JW, Bleyer WA, Willman $\mathrm{CL}$ et al. Cell surface expression of the multidrug resistance P-glycoprotein (P-170) as detected by monoclonal antibody
MRK-16 in pediatric acute myeloid leukemia fails to define a poor prognostic group: a report from the Childrens Cancer Group. Leukemia 1995; 9: 2042-2048.

24 Steinbach D, Furchtbar S, Sell W, Lengemann J, Hermann J, Zintl F et al. Contrary to adult patients, expression of the multidrug resistance gene (MDR1) fails to define a poor prognostic group in childhood AML. Leukemia 2003; 17: 470-471.

25 Pallis M, Das-Gupta E. Flow cytometric measurement of functional and phenotypic p-glycoprotein. In: Blumenthal RD (ed). Chemosensitivity, Vol. 2 Humana Press: Totowa, 2005.

26 Pallis M, Fisher J, Truran L, Grundy M, Russell N, Burnett A. Reproducible measurements of AML blast p-glycoprotein function in two centre analysis. Blood 2005; 105: 1367-1368.

27 Cheson BD, Bennett JM, Kopecky KJ, Buchner T, Willman CL, Estey $\mathrm{EH}$ et al. Revised recommendations of the International Working Group for diagnosis, standardization of response criteria, treatment outcomes, and reporting standards for therapeutic trials in acute myeloid leukemia. J Clin Oncol 2003; 21: 4642-4649.

28 Leith CP, Kopecky KJ, Godwin J, McConnell T, Slovak ML, Chen $\mathrm{IM}$ et al. Acute myeloid leukemia in the elderly: assessment of multidrug resistance (MDR1) and cytogenetics distinguishes biologic subgroups with remarkably distinct responses to standard chemotherapy. A Southwest Oncology Group Study. Blood 1997; 89: 3323-3329.

29 Burnett A, Hills R, Milligan D, Hunter A, Goldstone A, Prentice A et al. Attempts to optimise induction and consolidation chemotherapy in patients with acute myeloid leukaemia: results of the MRC AML15 trial. Blood 2009; 114: 200.

30 Solary E, Drenou B, Campos L, De Cremoux P, Mugneret F, Moreau $\mathrm{P}$ et al. Quinine as a multidrug resistance inhibitor: a phase III multicentric randomized study in adult de novo acute myelogenous leukemia. Blood 2003; 102: 1202-1210.

31 Jawad M, Seedhouse C, Mony U, Grundy M, Russell NH, Pallis M. Analysis of factors that affect in vitro chemosensitivity of leukaemic stem and progenitor cells to gemtuzumab ozogamicin (Mylotarg) in acute myeloid leukaemia. Leukemia 2010; 24: 74-80.

32 van den Heuvel-Eibrink MM, Wiemer EA, de Boevere MJ, van der Holt B, Vossebeld PJ, Pieters R et al. MDR1 gene-related clonal selection and P-glycoprotein function and expression in relapsed or refractory acute myeloid leukemia. Blood 2001; 97: 3605-3611.

33 van der Pol MA, Broxterman HJ, Pater JM, Feller N, van der Maas M, Weijers GW et al. Function of the ABC transporters, P-glycoprotein, multidrug resistance protein and breast cancer resistance protein, in minimal residual disease in acute myeloid leukemia. Haematologica 2003; 88: 134-147.

34 Leith CP, Kopecky KJ, Chen IM, Eijdems L, Slovak ML, McConnell TS et al. Frequency and clinical significance of the expression of the multidrug resistance proteins MDR1/P-glycoprotein, MRP1, and LRP in acute myeloid leukemia: a Southwest Oncology Group Study. Blood 1999; 94: 1086-1099.

35 van den Heuvel-Eibrink MM, van der Holt B, te Boekhorst PAW, Pieters R, Schoester M, Lowenberg B et al. MDR 1 expression is an independent prognostic factor for response and survival in de novo acute myeloid leukaemia. Br J Haematol 1997; 99: 76-83.

36 Damiani D, Tiribelli M, Raspadori D, Michelutti A, Gozzetti A, Calistri $\mathrm{E}$ et al. The role of MDR-related proteins in the prognosis of adult acute myeloid leukaemia (AML) with normal karyotype. Hematol Oncol 2007; 25: 38-43.

37 Marzac C, Teyssandier I, Calendini O, Perrot JY, Faussat AM, Tang R et al. Flt3 internal tandem duplication and P-glycoprotein functionality in 171 patients with acute myeloid leukemia. Clin Cancer Res 2006; 12: 7018-7024.

38 Schaich M, Soucek S, Thiede C, Ehninger G, Illmer T. MDR1 and MRP1 gene expression are independent predictors for treatment outcome in adult acute myeloid leukaemia. Br J Haematol 2004; 128: 324-332.

39 Del Poeta G, Venditti A, Stasi R, Aronica G, Cox MC, Buccisano F et al. P-glycoprotein and terminal transferase expression identify prognostic subsets within cytogenetic risk classes in acute myeloid leukemia. Leuk Res 1999; 23: 451-465.

This work is licensed under the Creative Commons Attribution-NonCommercial-No Derivative Works creativecommons.org/licenses/by-nc-nd/3.0/ 